
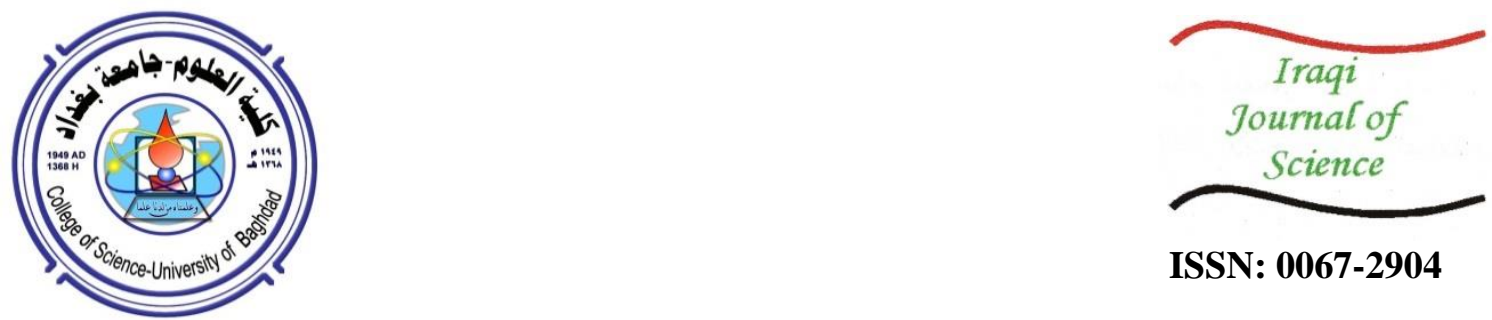

ISSN: 0067-2904

\title{
A Model to Compute the Solar Parameters in Relation to Determining the Optimal Angles for Solar Panels in Many Locations in Iraq
}

\author{
Thaer O. Roomi ${ }^{* 1}$, Hussain A. Nemah ${ }^{2}$, and Ramiz M. Shubbar ${ }^{3}$ \\ ${ }^{I}$ Department of Atmospheric Sciences, College of Science, Mustansiriyah University, Baghdad, Iraq \\ ${ }^{2}$ Department of Training and Development, Daura Refinery, Midland Refineries Company, Baghdad, Iraq
}

Received: $10 / 1 / 2021$

Accepted: 4/4/2021

\begin{abstract}
Directing solar panels in a way that collects the largest possible amount of solar energy is still attracting a lot of attention due to the continuous need to get clean, inexpensive renewable energy. Iraq is one of the countries characterized by the abundance of solar energy but the investment in this field has been far below ambition. In this study, an application developed with the visual basic programing language was used to compute precisely various solar angles and parameters, as a powerful tool for engineers and researchers. The outputs of the model were tested and discussed in detail. The air mass values were also computed for three cities: Mosul, Baghdad, and Basra. The results showed that the best time to acquire the solar radiation would be from 10 am to $2 \mathrm{pm}$ (local time), the period that has the lowest values of air mass. Additional useful calculations that can be estimated by the application were the terrestrial irradiances from four empirical models for the clear sky: Roledo-Soler, Adnot, Kasten - Czeplak, and Berger-Duffie. The calculated values of terrestrial irradiance were compared with observed data measured by automatic weather station. The application simulated the actual values with some deviations due to the existence of clouds and aerosols. Kasten - Czeplak model was recommended to be used in Iraq since it was the best model to simulate the measured values. The comparison between the model's output and the measured values on a daily basis on the $21^{\text {st }}$ of June showed good agreement. The study suggested that the solar panels should face the south direction with a change of the tilt angle of the panels from $25^{\circ}$ in June to a value of $60^{\circ}$ each month towards the coldest months by an increment of 5 degrees.
\end{abstract}

Key words: Solar model, Solar panels, Air mass, Terrestrial irradiance.

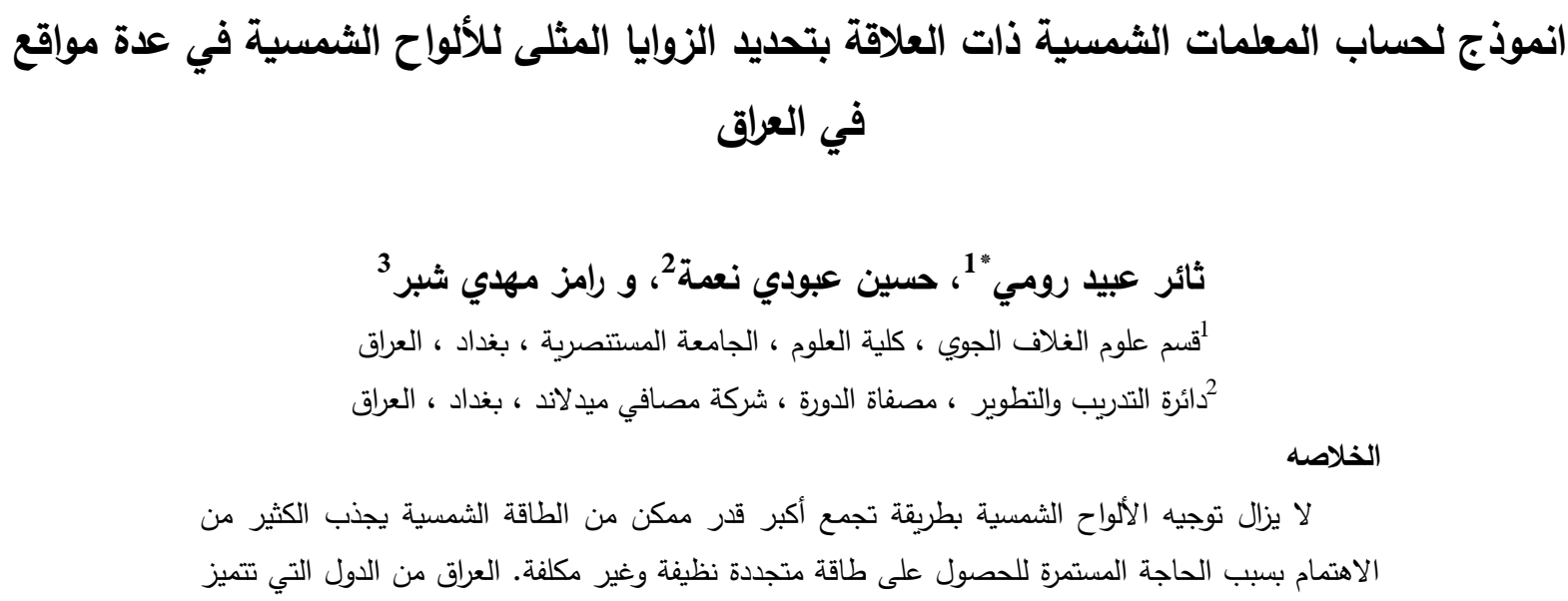

* Email: roomi.atmsc@uomustansiriyah.edu.iq 


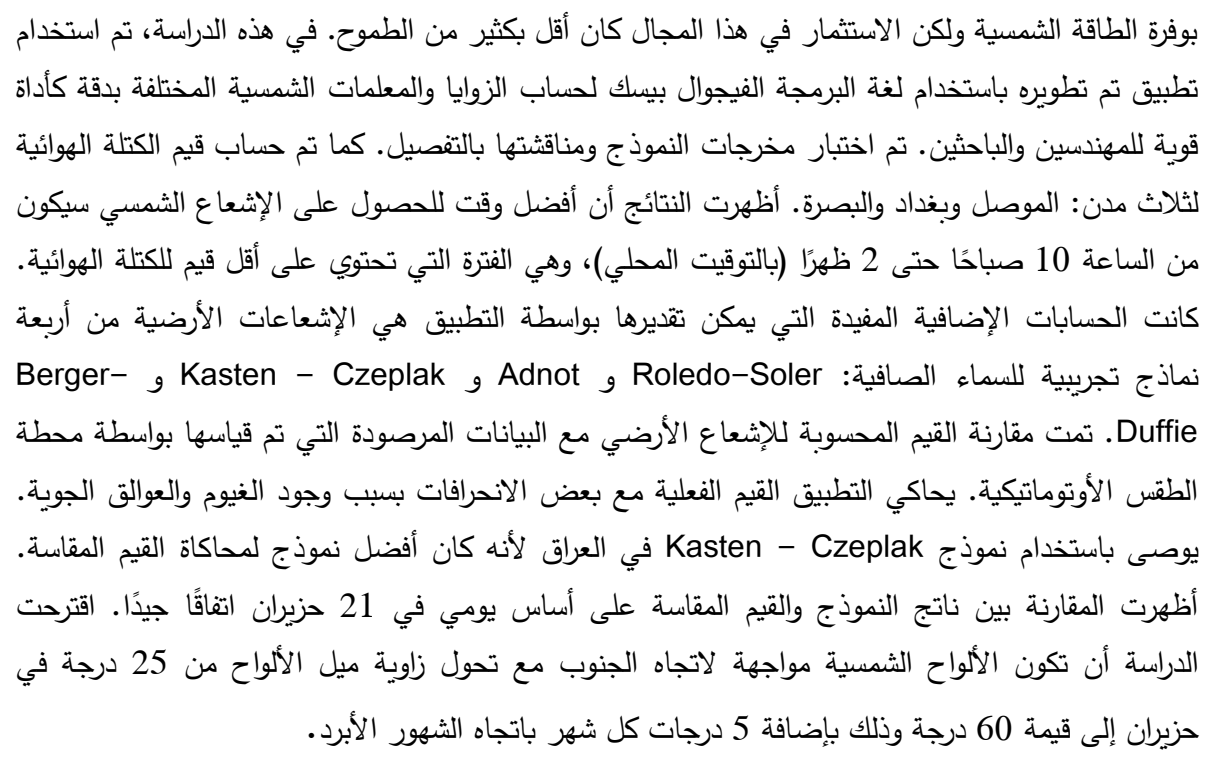

\section{Introduction}

Solar irradiance drives our weather and climate [1] and offers energy that is clean, cheap, and renewable. The solar energy research and technology have attracted increasing attention in the last decades as a promising alternative to the use of fossil fuels that pollute the atmosphere and enhance the climate change effects. A great deal of research work was devoted to improve the modeling and technical aspects of solar panels and collectors. Middle East is a rich spot of solar radiation but ,at the same time, it suffers from some climatic obstacles such as dust [2]. However, mineral dust is not the only pollutant that decrease the solar irradiance reaching the earth surface. Air molecules absorb, scatter, and reflect the sun light; many aerosols in addition to the clouds affect the overall portion of solar energy [3]. Air mass (AM) refers to the optical path length through the atmosphere where light is scattered and absorbed [4]. It is described as the relative length of the direct-beam path through the atmosphere compared with a vertical path directly to sea level [5]. Hence, the air mass is 1.0 when the sun is directly overhead, 1.5 when the sun is $48.2^{\circ}$ from vertical (zenith) and 2.0 when the sun is at $60.0^{\circ}$ [6]. The sun elevation is a function of space and time. It affects the amount of energy reaching the solar panels and collectors. The closer the regions are to the equator, the higher the sun elevation, the lowest the air mass and the higher the solar energy [7]. In winter, the celestial path of the sun is closer to the horizon than in summer [6]. Figure (1) shows the solar angles that determine the position of the sun with respect to earth.

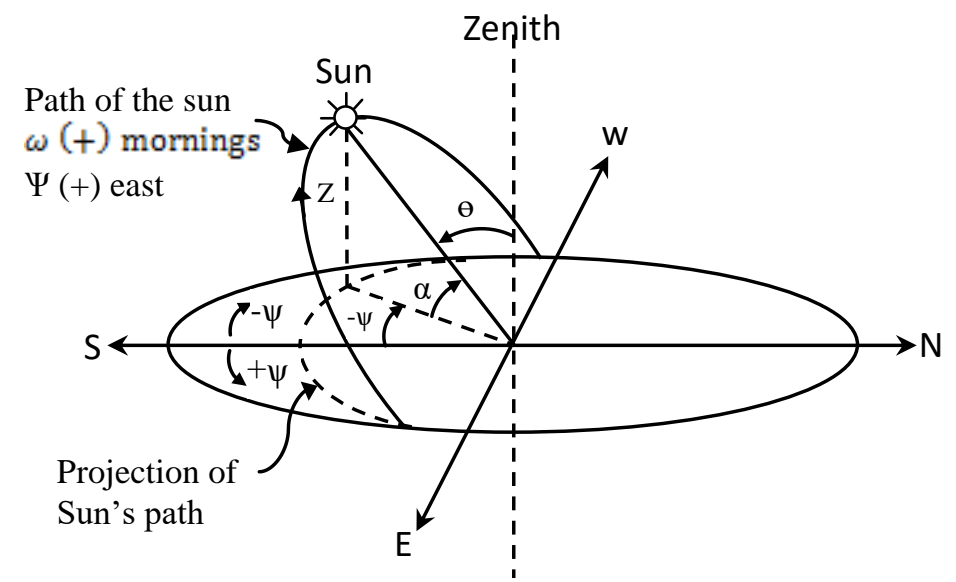

Figure 1-Solar angles 
In this study, a model consisting of many equations of solar mechanics and solar energy is proposed and developed using visual basic dot net scripts and interfaces. The main objectives are to study and estimate the various solar parameters, air mass, extraterrestrial and terrestrial irradiance, and to find the optimal tilt angle of the solar panels in some locations in Iraq.

\section{The sun's position and irradiance}

It is important to explain the celestial mechanics, which describe the position of the sun in the sky at any moment [8], [9].

The elevation angle $(\alpha)$ is the angle between the sun light and the horizontal level:

$$
\sin (\alpha)=\sin (\varphi) \sin (\delta)+\cos (\varphi) \cos (\delta) \cos (\omega)
$$

where, $\varphi$ is the local latitude, $\delta$ is the declination angle [10],

$$
\delta=23.45^{\circ} \sin \left[\frac{360}{365}\left(284+d_{n}\right)\right]
$$

$d_{n}$ is the day number in the year, e.g. 1 for $1^{\text {st }}$ January.

$\omega$ is the hour angle that describes the angular movement of the sun from the noon (12 pm). The sun travels $15^{\circ}$ longitudes per hour being negative value in the morning, positive in the evening, and zero at noon [11],

AST is the apparent solar time [12],

$$
\omega=15(A S T-12)
$$

$$
A S T=L S T+E T \pm 4(S L-L L)-D S
$$

is the local standard time, $E T$ is the equation of time, $S L$ is the standard longitude, $L L$ is $L S T$ the local longitude, and DS is the summer time ( 0 or 60 minutes).

$$
\begin{gathered}
E T=9.87 \sin (2 B)-7.53 \cos (B)-1.5 \sin (B)[\mathrm{min}] \\
B=(N-81) \frac{360}{364}
\end{gathered}
$$

From equation 1, the hour angle at the sunrise and sunset $(\alpha=0)$ can be written as [13],

$$
\omega_{s}=\mp \cos ^{-1}(-\tan \varphi \cdot \tan \delta)
$$

The solar azimuth $\psi$ is the angle between the sunlight projection and the longitude. In the northern hemisphere, the azimuth angle equals to $0^{\circ}$ for the south-facing surface, and $180^{\circ}$ for the north-facing surface, 0 to $180^{\circ}$ for the west - facing surface, and 0 to $-180^{\circ}$ for the east facing surface,

$$
\sin (\psi)=\frac{\cos (\delta) \sin (\omega)}{\cos (\alpha)}
$$

\section{Air Mass}

The air mass characterizes the path travelled by the sunlight through the atmosphere to the sea level. It equals zero for the extraterrestrial space or if one thinks of the earth without atmosphere. Near the equator, when the sun is at the zenith, the air mass is regarded as 1 , since the solar rays travels the shortest path. The simplest form of air mass is [14],

$$
A M=\frac{1}{\cos \theta}
$$

where $\theta$ is the zenith angle ( the angle between the sunlight and the vertical) and is given by,

$$
\theta=90^{\circ}-\alpha
$$

At $\theta=60^{\circ}, A M=2$ which means that the solar radiation will travel a path two times longer than at $\theta=0^{\circ}$ and hence will be greatly attenuated and less energy will reach the solar panels, for instance.

The above formula considers the density constant for the atmosphere and ignores the earth's curvature using the geometry of a parallel plate [4]. For zenith angle greater than $80^{\circ}$, 
equation 9 fails to give accurate values of AM. Kasten and Young[15], in 1989, suggested the following formula that best fits the measured data for all expected values of zenith angles,

$$
A M=\frac{1}{\cos \theta+0.50572(96.07995-\theta)^{-1.6354}}
$$

\section{Solar Irradiance reaching the solar panels}

The extraterrestrial radiation $I_{0}$, or the radiation that reaches the outer part of the earth atmosphere is regarded as constant (Solar constant $\approx 1367.7$ ) for most applications. However, it varies slightly throughout the year and can be calculated by taking into account the astronomical facts according to the following formula [4]:

$$
I_{\circ}=1367.7\left(1+0.33 \cos \left(\frac{2 \pi d_{n}}{365}\right)\right)
$$

On the other hand, air molecules and aerosols attenuate the terrestrial radiation reaching the earth surface. Calculation of the solar irradiance reaching the earth surface is a bit complicated process because some of the light is absorbed and scattered by the atmosphere. Many models in literature are used to estimate the solar irradiance, mostly with clear sky assumption [16]. The attenuation is a function of the zenith angle. High zenith angles result in high air mass and more interaction between the solar radiation and the atmosphere [4]. There are many simple formulas to estimate the Global Horizontal Irradiance (GHI), for instance [17], [18]:

(a) Model 1 (Roledo- Soler Model),

(b) Model 2 (Adnot Model)

$$
G H I=1159.24(\operatorname{Cos} \theta)^{1.179} \exp \left(-0.0019\left(90^{\circ}-\theta\right)\right)
$$

(c) Model 3 (Kasten -Czeplak Model)

$$
G H I=951.39(\operatorname{Cos} \theta)^{1.15}
$$

(d) Model 4 (Berger-Duffie Model)

$$
G H I=910 \operatorname{Cos}(\theta)-30
$$

$$
G H I=1366.1 \times 0.7 \operatorname{Cos}(\theta)
$$

It is worth mentioning that there are many other models that estimate the GHI depending on variables other than the zenith angle, such as e air temperature [19].

\section{Materials and Methods}

\section{Data and location}

The dataset of the observed global horizontal irradiance was acquired from the Department of Atmospheric Sciences, College of Science, Mustansiriyah University. The dataset was measured by an automatic weather station (DAVIS VANTAGE PRO2) installed on the roof of the department building $(33.3672 \mathrm{~N}, 44.4034 \mathrm{E}$, Altitude $=56 \mathrm{~m})$. This dataset was used to evaluate the calculated values of the global irradiance. The scripts of the algorithm were written using Visual Basic dot net programing language to compute the various solar parameters. Figure 2 shows the weather station and Figure 3 shows the main interface of the developed application. 


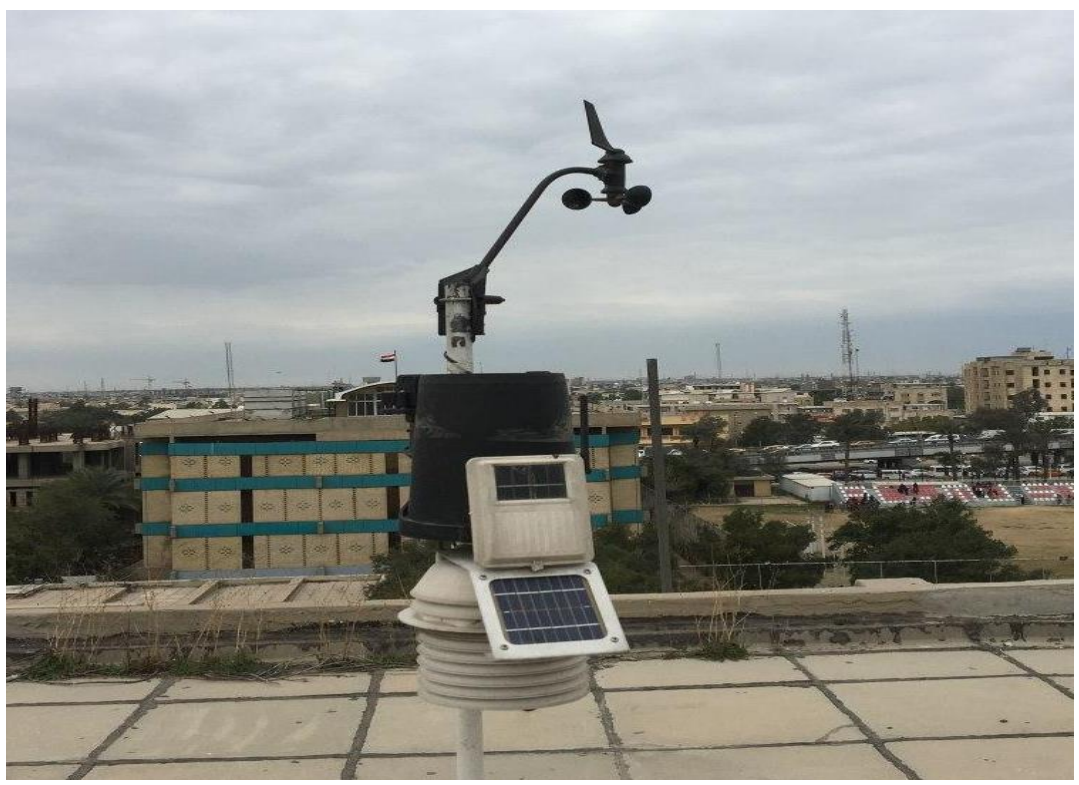

Figure 2- The automatic weather station.

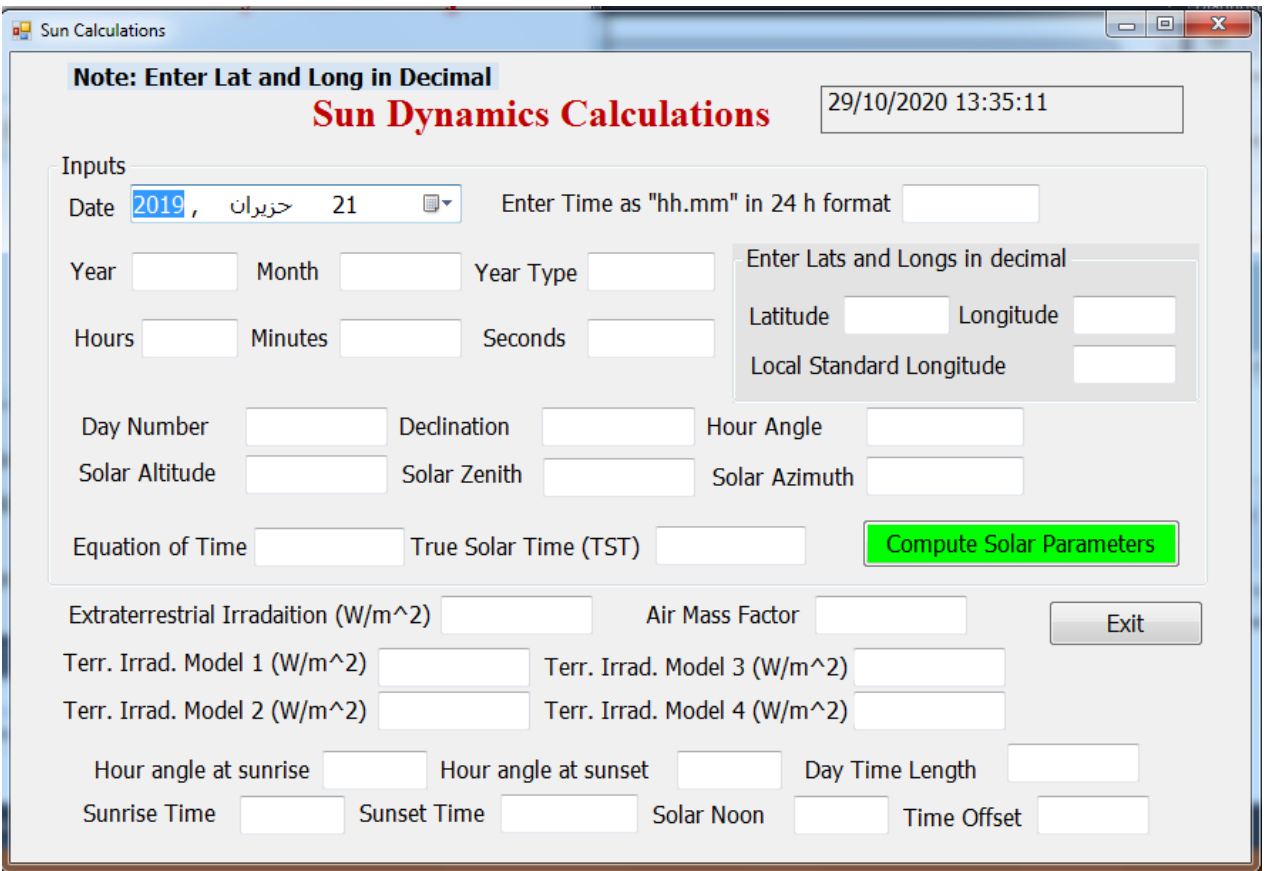

Figure 3- The main Interface of the application.

\section{The Annual and Diurnal Change of Solar Angles throughout a Year}

The annual change of solar angles and equation of time for Baghdad is depicted in Figure 3. The time was fixed at 10 am ( local time). The daily change of solar angles and equation of time for Baghdad on the $21^{\text {st }}$ of June are visualized in Figure 4. 


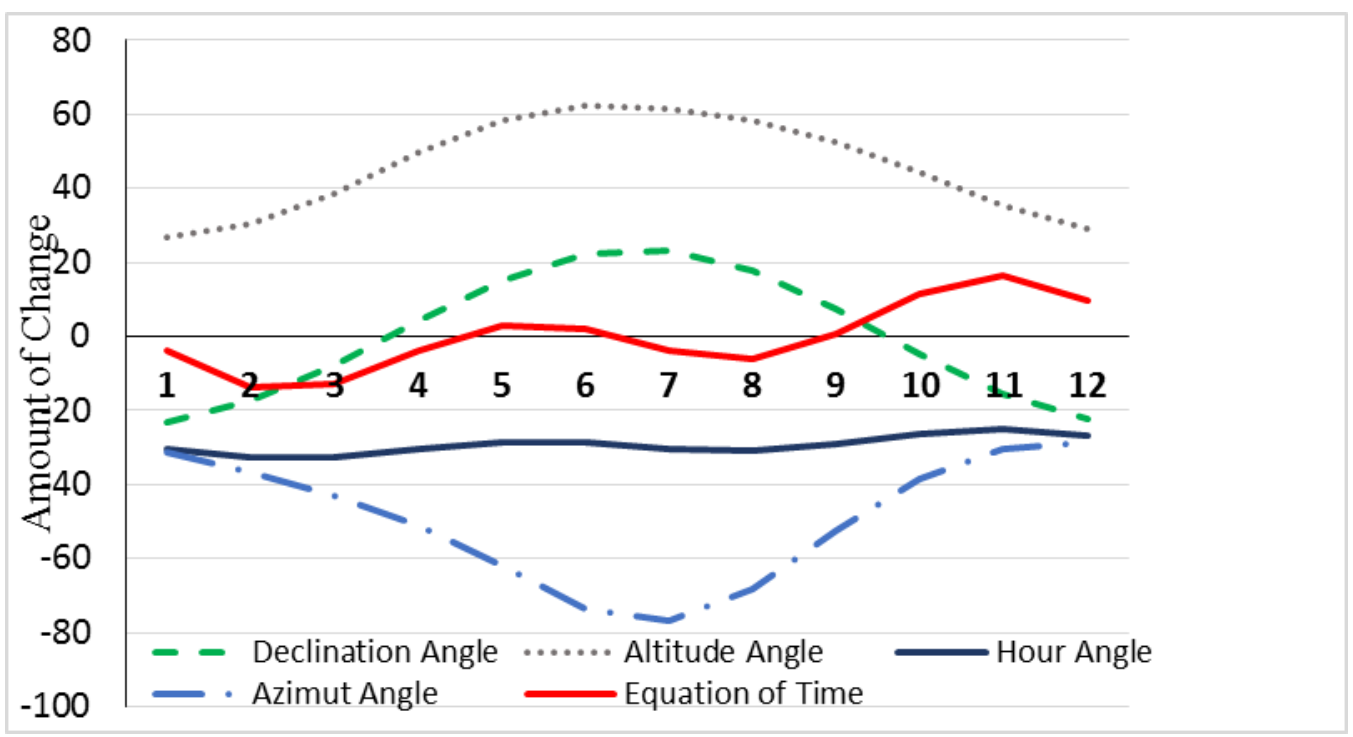

Figure 3-Change of solar angles and equation of time for Baghdad throughout the year at 10 am for the first day of each month.

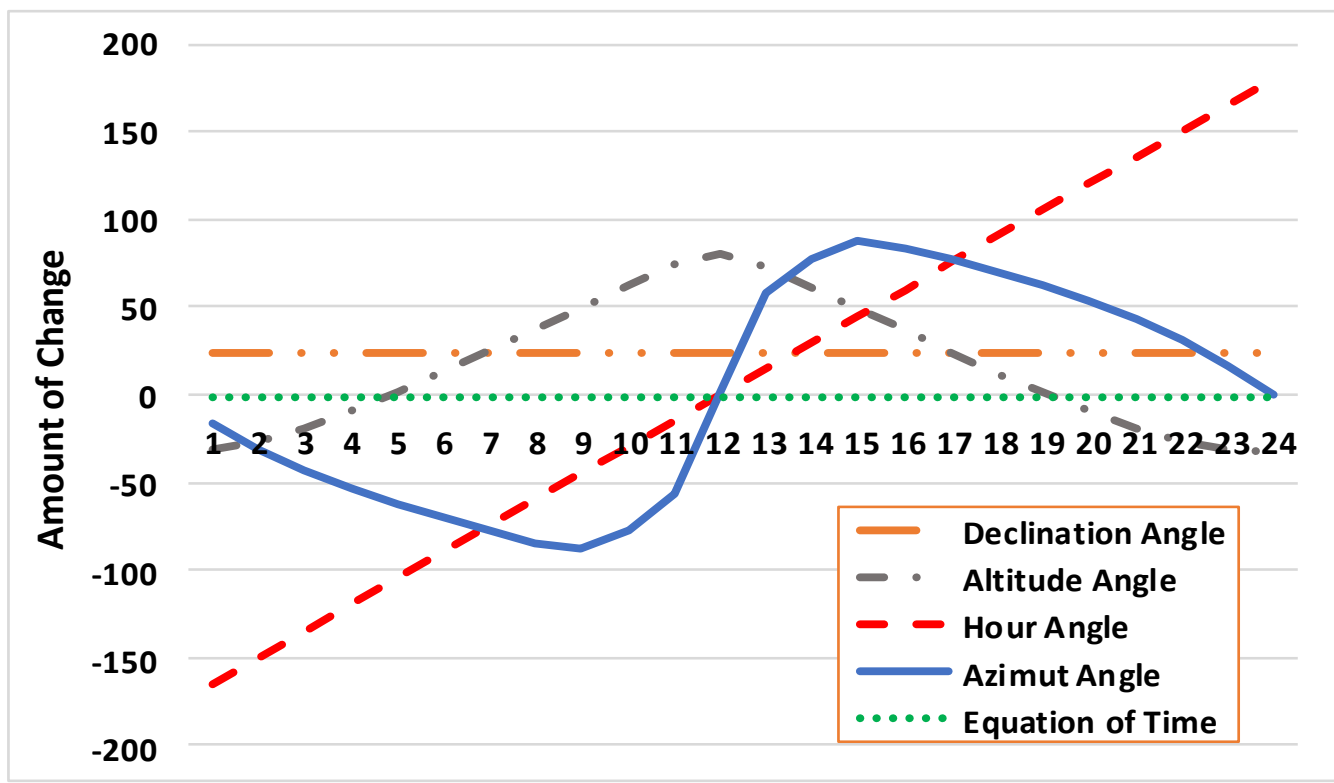

Figure 4-The change of solar angles and equation of time for Baghdad during 24 hours on the $21^{\text {st }}$ of June 2020.

\section{Calculation of Optical Air Mass}

The optical air mass (or just air mass) for three cities were calculated by Equation 11 on Day 21 of each month. The Three cities representative to north, middle, and south of Iraq were Mosul $\left(36.34^{\circ} \mathrm{N}, 43.15^{\circ} \mathrm{E}\right)$, Baghdad $\left(33.31^{\circ} \mathrm{N}, 44.36^{\circ} \mathrm{E}\right)$, and Basra $\left(30.52^{\circ} \mathrm{N}, 44.36^{\circ}\right.$ E),respectively (See Figures 5-7). 


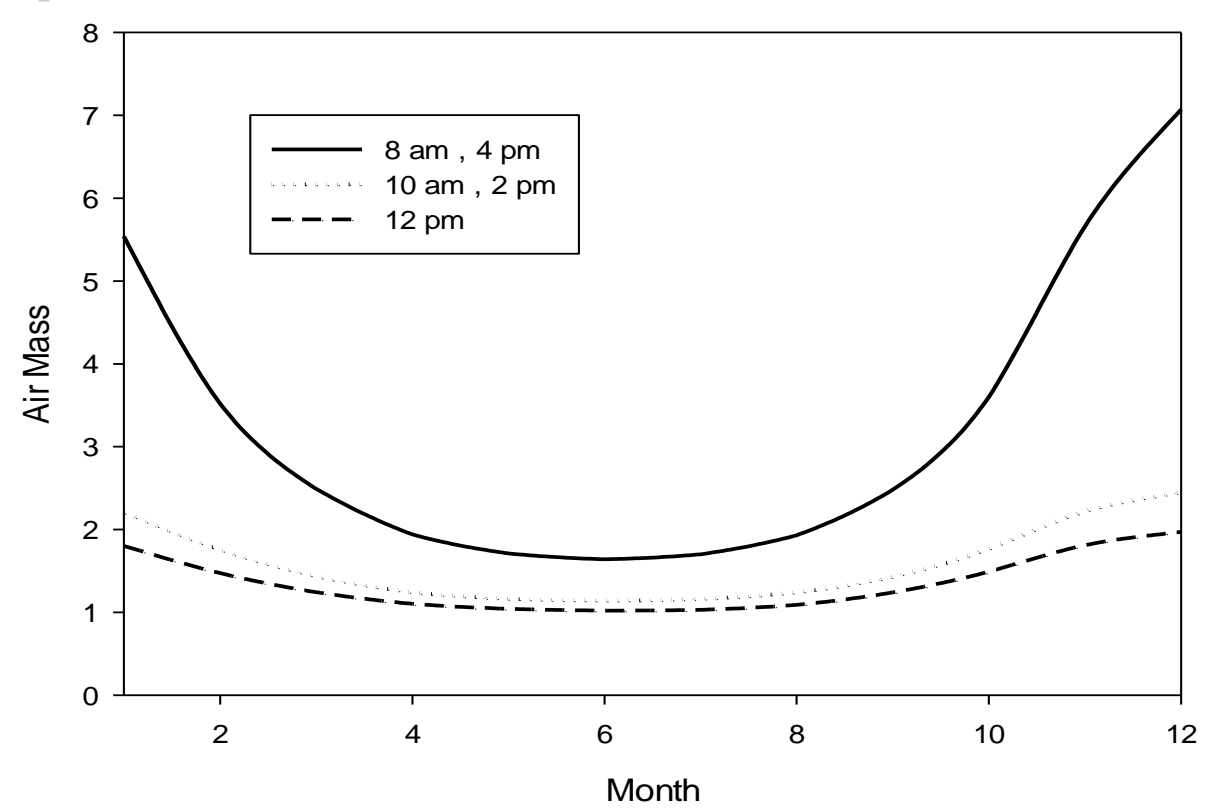

Figure 5- The annual change of air mass for Mosul city on day 21 of each month (at 8 am, 10 am, 12 pm, 2 pm, and 4 pm).

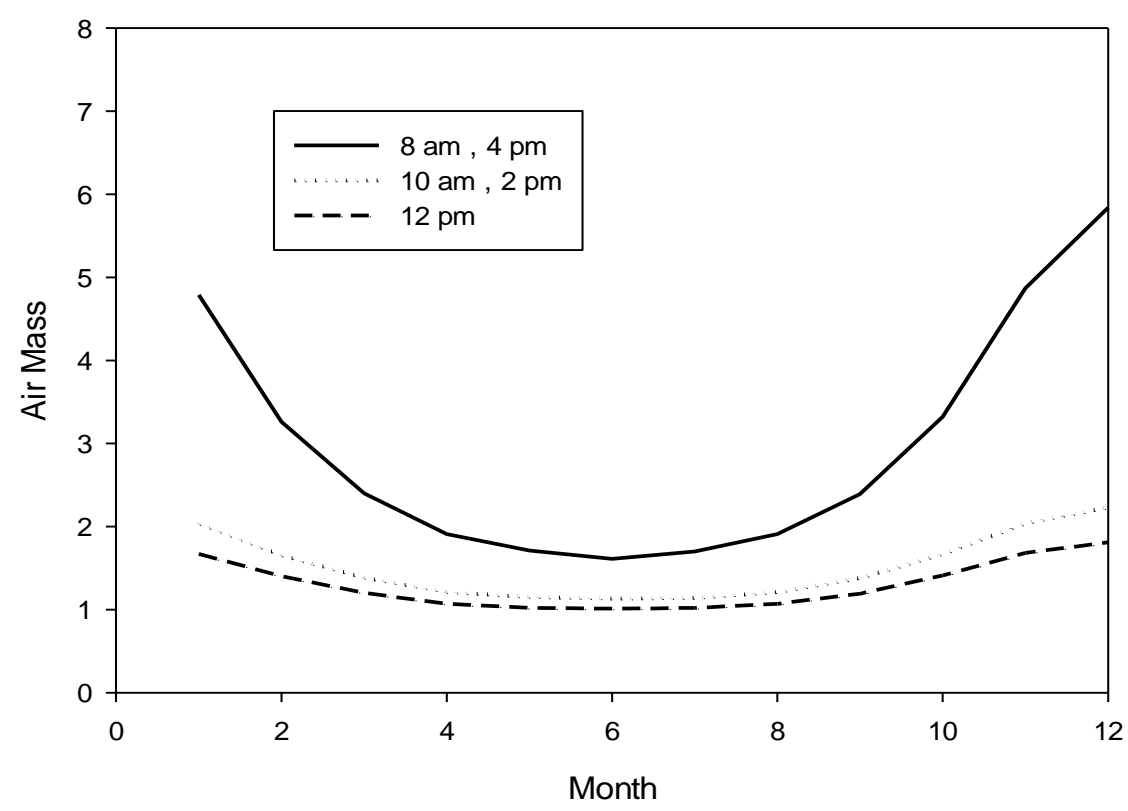

Figure 6- The annual change of air mass for Baghdad city on day 21 of each month (at 8 am, $10 \mathrm{am}, 12 \mathrm{pm}, 2 \mathrm{pm}$, and $4 \mathrm{pm}$ ). 


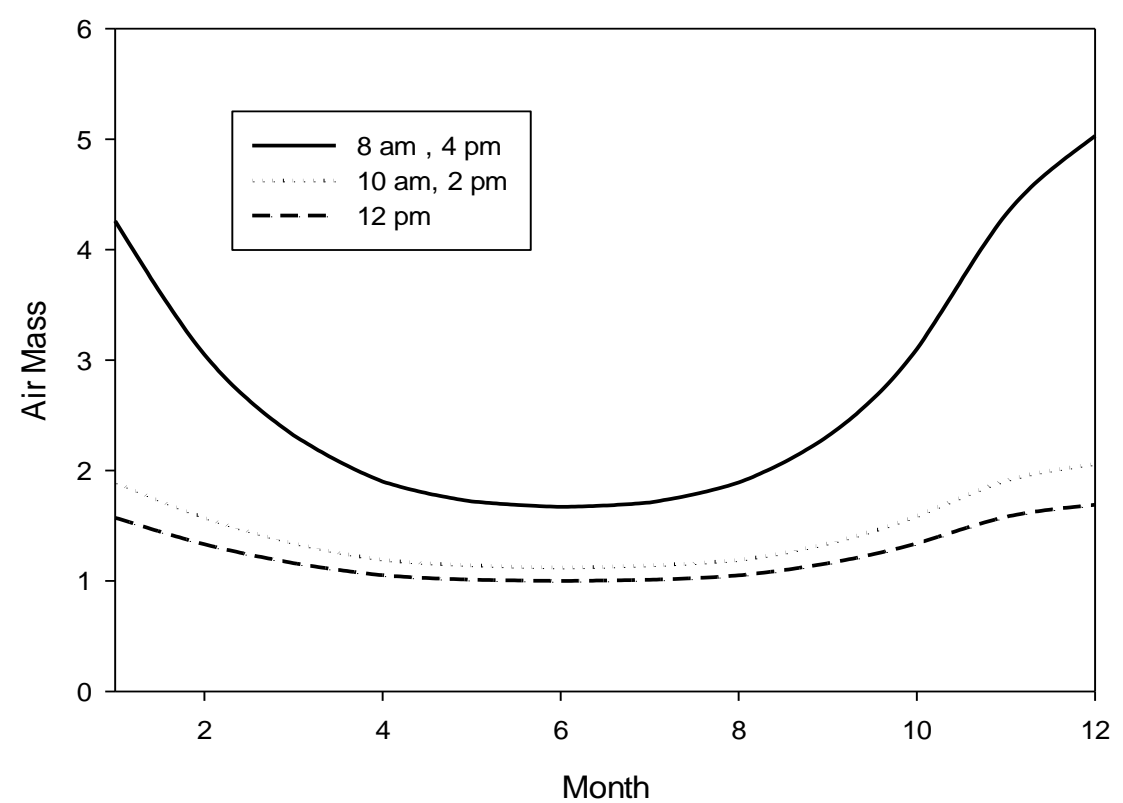

Figure 7-The annual change of air mass for Basra city on day 21 of each month (at 8 am, 10 am, $12 \mathrm{pm}, 2 \mathrm{pm}$, and $4 \mathrm{pm})$.

\section{Calculation of Extraterrestrial and Terrestrial Global Horizontal Irradiance}

The global extraterrestrial and terrestrial horizontal irradiance were calculated for Baghdad city every 10 days in 2019. The calculations of the extraterrestrial irradiance were based on Equation (12) while the calculations of terrestrial irradiance were based on Equations (1316). The latter calculated values were compared with the observed values obtained from the automatic weather station. The results are shown in Figures (8-9). Additional investigations were made on hourly change basis on the $21^{\text {st }}$ of June 2019 and on the $21^{\text {st }}$ of December 2019 for Baghdad city as in Figure 10 and Figure 11.

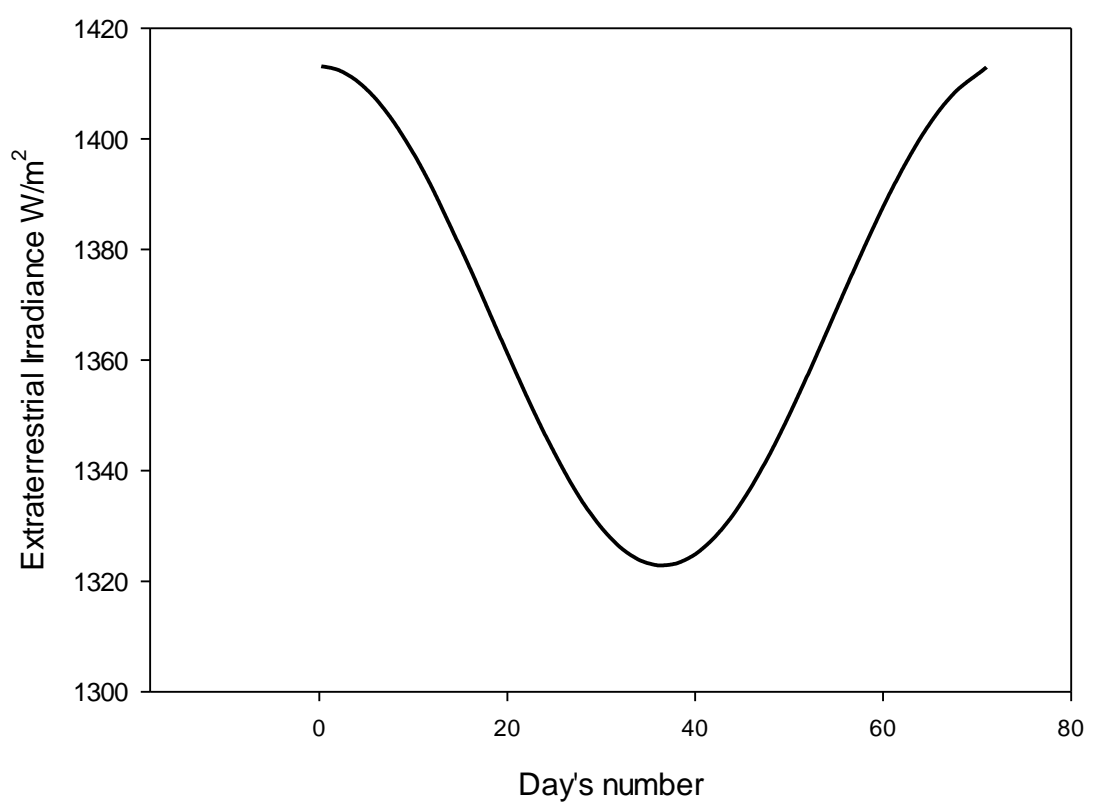

Figure 8-The annual change of extraterrestrial irradiance for Baghdad city at 12 pm (Baghdad local time). 


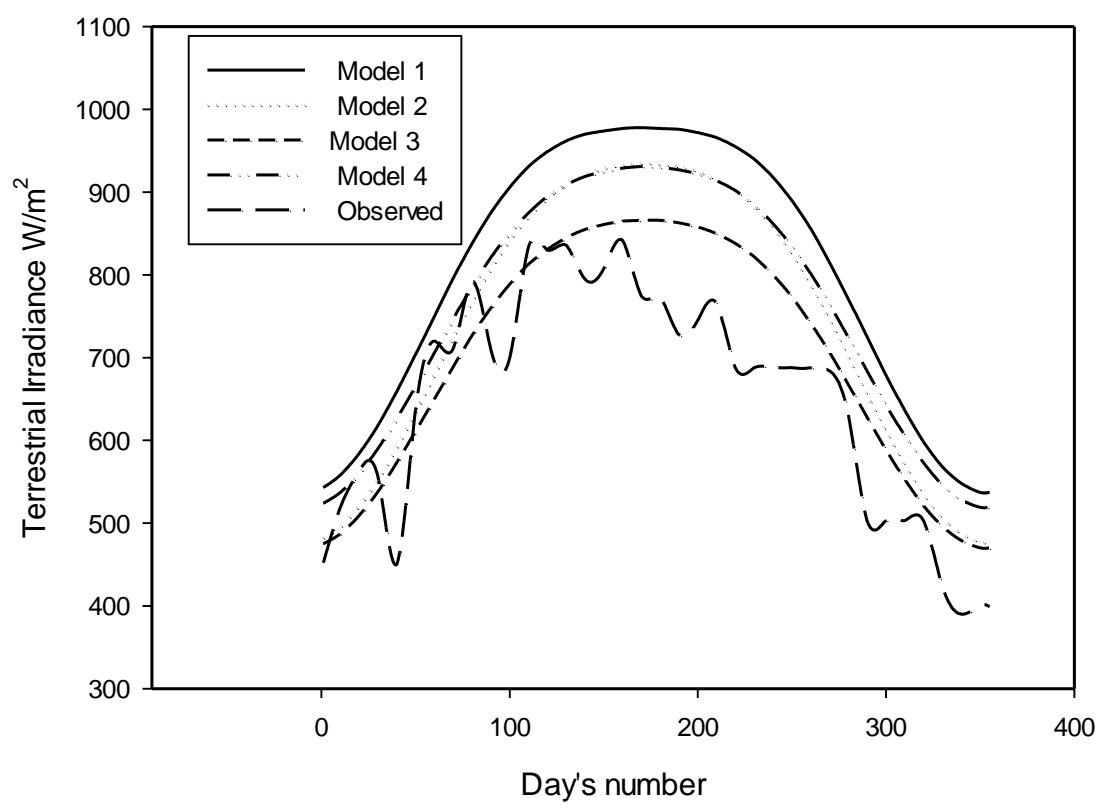

Figure 9- The annual change of terrestrial irradiance for Baghdad city at 12 pm (Baghdad local time) during 2019 for four empirical models and the observed one.

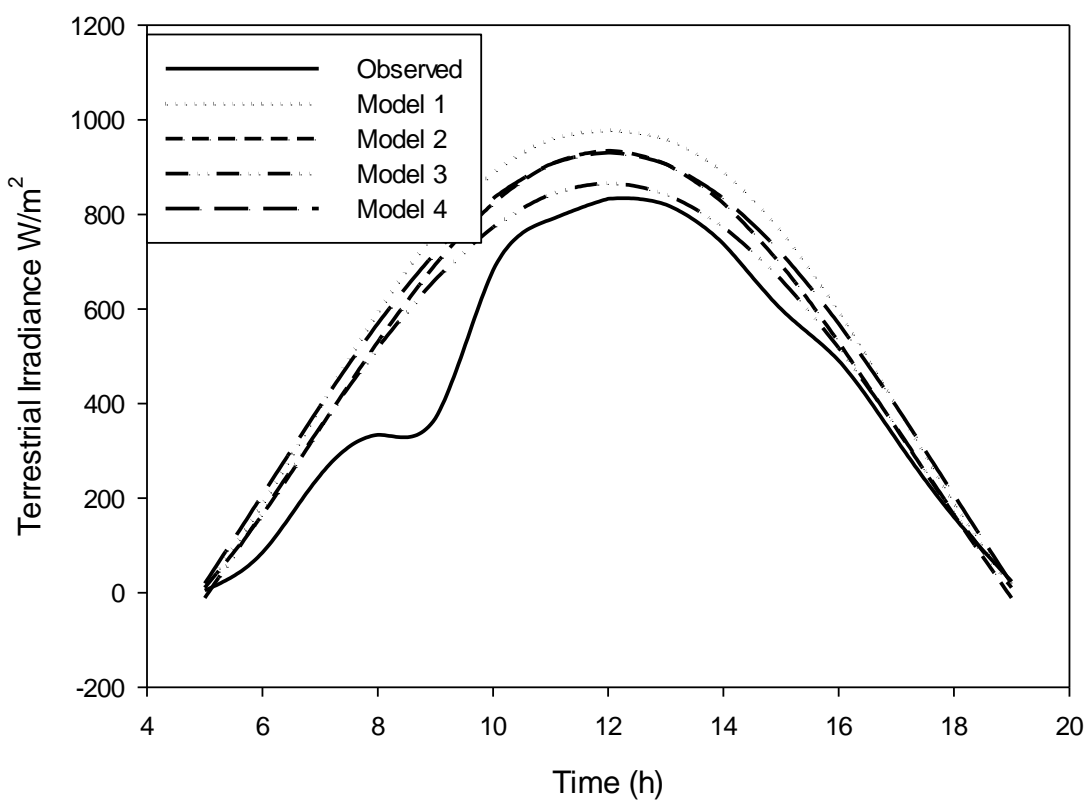

Figure 10-The diurnal change of terrestrial irradiance for Baghdad city on the $21^{\text {st }}$ of June 2019 for four empirical models and the observed one. 


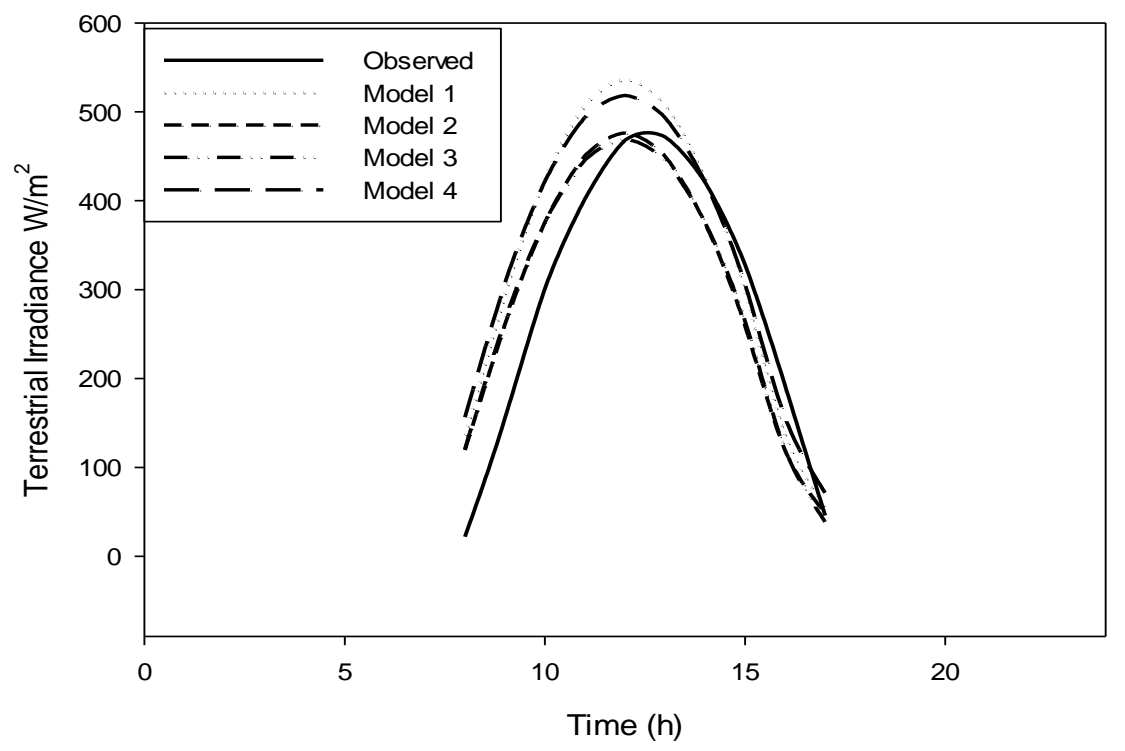

Figure 11-The diurnal change of terrestrial irradiance for Baghdad city on the $21^{\text {st }}$ of December 2019 for four empirical models and the observed one.

\section{Results and Discussion}

The application, which was developed with Visual Basic programing language, has a powerful interface that offers many outputs.It is beneficial for any researcher or engineer who works on solar facilities. The application program has been confirmed to be free of bugs and errors.

The study of the curves of solar angles and equation of time in Figure 3 showed that the declination and altitude angles are increasing during the summer days and decreasing toward winter. On the contrary, the azimuth angle is decreasing toward the summer solstice. The values of the hour angle depend solely on time and hence it was still constant during the year since the time was fixed at $10 \mathrm{am}$. The hour angle was negative in the morning and positive in the evening. Equation of time was changing in value and sign during the year.

From Figure 4, it is clear that the declination angle and equation of time do not change throughout the same day since it depends on the day's number. Altitude angle was greater at noon and smaller at sunrise and sunset. Hour angle changed linearly from negative in the morning to positive in the evening. Whereas the azimuth angle changed from negative in the morning to positive in the evening and equal to zero at $12 \mathrm{pm}$ and $12 \mathrm{am}$. The equation of time was equal to zero on the $21^{\text {st }}$ of June. The curves in Figures 3-4 can give visual tool to understand the change of the position of the sun with respect to earth.

The air mass charts in Figures (5-7) for the three cities: Mosul, Baghdad, and Basra showed distinct differences. If one takes air mass value of 2 as a level of reliable factor, the best time to acquire the solar radiation will be at 12 local time. The solar panels would be in perfect operation at 12. The period extended from 10 am to $2 \mathrm{pm}$ is also good to get a great deal of solar radiation all over the year. On the other hand, the periods before 10 am and after $4 \mathrm{pm}$ are far from the acceptable periods of getting the required radiation except in the period from March to September. Hence, one should not pay much attention in tracking radiation for the imperfect times at the process of changing the tilt angle of the solar panels. In this context, it was noticed that the criteria of getting the solar radiation are better for Basra than for Baghdad and Mosul because of the small value of air mass in Basra.

\section{Extraterrestrial and Terrestrial Irradiances}

The extraterrestrial irradiance reaching the outer atmosphere is not exactly constant 
throughout the year. It does reveal some slight changes ranging from 1320 to $1413 \mathrm{~W} / \mathrm{m}^{2}$ as in Figure 8. The highest values were in the winter and the least in the summer. The reason is that the earth is closer to the sun in winter (147 million $\mathrm{km}$ in January, 152 million $\mathrm{km}$ in July) [20]. All the recorded and calculated irradiance values on a horizontal surface on earth were under $1000 \mathrm{~W} / \mathrm{m}^{2}$ because of the air mass that attenuate the solar radiation. In Figure 9, the curve drawn for the global horizontal irradiance (GHI), or simply the terrestrial irradiance, versus day's number resembled that of four empirical models, with the observed values measured by an automatic weather station. The curves showed bell-shaped lines with a peak located in the middle of the year on June $21^{\text {st }}$. The models simulate the actual values to some extent. The differences may belong to the existence of clouds and aerosols that attenuate the solar radiation. The model of Kasten - Czeplak, was the best to simulate the measured values and therefore it is recommended to estimate the global horizontal irradiance in the Iraqi cities. The comparison between the models output and the measured values on a hourly basis on the $21^{\text {st }}$ of June showed good agreement in a clear sky condition in the middle of summer(Figure 10). On the $21^{\mathrm{st}}$ of December, the measured values did not match the models in the morning(Figure 11). This can be justified by the presence of fog, haze, or even stratus clouds in the morning, which may have disappeared in the afternoon.

\section{The Orientation of Solar Panels}

The study showed that the solar panels should face the south direction. Also, the tilt angle of the panels (which is equal to the zenith angle) should gradually be changed from a value of 25 degrees in June to a value of 60 degrees towards the cooler months with an monthly increment of 5 degrees..

\section{Conclusions}

1. The application of solar parameters which was developed with visual basic programing language offers a powerful interface that compute the various parameters required by users and researchers. The application calculated with great precision the various solar angles and parameters and the measurements were discussed.

2. The air mass calculations for three cities: Mosul, Baghdad, and Basra showed distinct differences. If one takes air mass value of 2 as a level of reliable factor, the best time to acquire the solar radiation will be at 12 local time. The solar panels would be in perfect operation at 12. The period extended from 10 am to $2 \mathrm{pm}$ is also good to get a high solar radiation all over the year. On the other hand, the periods before 10 am and after $4 \mathrm{pm}$ are far from the acceptable periods of getting the required radiation except in the period from March to September. Hence, one should not pay much attention in tracking radiation for the imperfect times at the process.

3. The curves of the global horizontal irradiance (the terrestrial irradiance) of the models: Roledo- Soler, Adnot, Kasten - Czeplak, and Berger-Duffie simulated the actual values to some extent. There were some differences that may be due to the existence of clouds and aerosols that attenuate the solar radiation. Kasten - Czeplak model was the best to simulate the measured values. So it is recommended to estimate the global horizontal irradiance in the Iraqi cities. The comparison between the models output and the measured values on an diurnal basis on the $21^{\text {st }}$ of June showed good agreement in a clear sky condition. The existence of clouds, haze, and aerosols lessened the agreement due to the attenuation of solar radiation.

4. The study showed that the solar panels should be facing south. Also, the tilt angle of the panels (which is equal to the zenith angle) should be gradually changed from a value of 25 degrees in June to a value of 60 degrees towards the cooler months with an monthly increment of 5 degrees.

\section{Acknowledgments}

The authors thank the Mustansiriyah University for offering all the facilities. Special thanks to 
the Department of Atmospheric Sciences for the dataset of automatic station that was used in this research.

\section{References}

[1] M. Wild et al., "The energy balance over land and oceans: an assessment based on direct observations and CMIP5 climate models," Clim. Dyn., vol. 44, no. 11-12, pp. 3393-3429, 2015, doi: 10.1007/s00382-014-2430-z.

[2] T. O. Roomi, K. N. Zeki, and A. F. Hassoon, "A Comprehensive Case Study of a Frontal Mineral Dust Storm in spring over Iraq," Iraqi J. Sci., vol. 58, no. 4B, pp. 2236-2251, 2017, doi: 10.24996/ijs.2017.58.4b.26.

[3] P. Yongsiriwith, P. Khoonphunnarai, R. Intarachumnum, and S. Kongmeetong, "The effects of clouds on solar radiation at Songkhla," J. Phys. Conf. Ser., vol. 1144, no. 1, pp. 1-6, 2018, doi: 10.1088/1742-6596/1144/1/012034.

[4] M. J. Reno, C. W. Hansen, and J. S. Stein, "Global Horizontal Irradiance Clear Sky Models: Implementation and Analysis," SANDIA Rep. SAND2012-2389 Unltd. Release Print. March 2012, no. March, pp. 1-66, 2012.

[5] A. H. Shnishil, S. S. Chid, M. J. Yaseen, and T. J. Alwana, "Influence of air mass on the performance of many types of PV modulus in Baghdad," Energy Procedia, vol. 6, pp. 153-159, 2011, doi: 10.1016/j.egypro.2011.05.018.

[6] T. M. \& A. I. A.-A. Al-maula, "Calculate and Analysis of Air Mass and Solar Angles of Mosul City Taha," vol. 27, no. 4, pp. 57-65, 2018.

[7] C. J. Riordan, R. L. Hulstrom, and D. R. Myers, "Influences of Atmospheric Conditions and Air Mass on the Ratio of Ultraviolet to Total Solar Radiation," Colorado, 1990.

[8] M. Abdurrahman et al., "Solar Elevation Angle and Solar Culmination Determination using Celestial Observation; A Case Study Of Hadejia Jigawa State, Nigeria," Int. J. Adv. Sci. Res. Eng., vol. 5, no. 9, pp. 08-17, 2019, doi: 10.31695/ijasre.2019.33482.

[9] M. Guo et al., "Optimal tilt angle and orientation of photovoltaic modules using HS algorithm in different climates of china," Appl. Sci., vol. 7, no. 10, pp. 1-12, 2017, doi: 10.3390/app7101028.

[10] E. Quansah et al., "Empirical Models for Estimating Global Solar Radiation over the Ashanti Region of Ghana," J. Sol. Energy, vol. 2014, pp. 1-6, 2014, doi: 10.1155/2014/897970.

[11] T. Khatib and W. Elmenreich, "A model for hourly solar radiation data generation from daily solar radiation data using a generalized regression artificial neural network," Int. J. Photoenergy, vol. 2015, pp. 1-13, 2015, doi: 10.1155/2015/968024.

[12] S. A. Kalogirou, Solar Energy Engineering Processes and Systems, 2nd ed. CA: Elsevier Inc., 2014.

[13] M. H. Chung, "Estimating Solar Insolation and Power Generation of Photovoltaic Systems Using Previous Day Weather Data," Adv. Civ. Eng., vol. 2020, pp. 1-13, 2020, doi: $10.1155 / 2020 / 8701368$.

[14] I. L. Alboteanu, C. A. Bulucea, and S. Degeratu, "Estimating solar irradiation absorbed by photovoltaic panels with low concentration located in Craiova, Romania," Sustain., vol. 7, no. 3, pp. 2644-2661, 2015, doi: 10.3390/su7032644.

[15] F. Kasten and A. T. Young, "Revised optical air mass tables and approximation formula," Appl. Opt., vol. 28, pp. 4735-4738, 1989.

[16] F. Antonanzas-Torres, R. Urraca, J. Polo, O. Perpiñán-Lamigueiro, and R. Escobar, "Clear sky solar irradiance models: A review of seventy models," Renew. Sustain. Energy Rev., vol. 107, pp. 374-387, 2019, doi: https://doi.org/10.1016/j.rser.2019.02.032.

[17] V. Badescu, "Verification of Some Very Simple Clear and Cloudy Sky," Sol. Energy, vol. 61, no. 4, pp. 251-264, 1997.

[18] L. ; A. S. Robledo, "Luminous efficacy of direct solar radiation for clear skies," Energy, vol. 25, no. 8, pp. 68019-7, 2000, doi: 10.1016/S0360-5442(00)00017-7.

[19] A. H. Ajil, "Evaluation and Comparison of Temperature-Based Models for The Prediction of The Monthly Average of Daily Global Solar Radiation for Baghdad City- Iraq," Iraqi J. Sci., vol. 61, no. 3, pp. 533-539, 2020, doi: 10.24996/ijs.2020.61.3.9.

[20] C. D. Ahrens and R. Henson, Essentials of Meteorology: An Invitation to the Atmosphere, 8th ed. Cengage Learning, 2018. 